\title{
Integrated assessment of environmental impact of Europe in 2010: data sources and extrapolation strategies for calculating normalisation factors
}

\author{
Serenella Sala ${ }^{1} \cdot$ Lorenzo Benini $^{1} \cdot$ Lucia $^{\text {Mancini }^{1}}{ }^{1}$ Rana Pant $^{1}$
}

Received: 10 April 2015 / Accepted: 18 August 2015 / Published online: 28 August 2015

(C) The Author(s) 2015. This article is published with open access at Springerlink.com

\begin{abstract}
Purpose Assessing comprehensively the overall environmental impacts of a region remains a major challenge. Within life cycle assessment (LCA), this evaluation is performed calculating normalisation factors (NFs) at different scales. Normalisation represents an optional step of LCA according to ISO 14040/44 which may help in understanding the relative magnitude of the impact associated to a product when compared to a reference value. In order to enhance the robustness and comprehensiveness of NFs, this paper presents a methodology for building an extended domestic inventory of emission and resources extraction. The domestic inventory refers to emissions and extractions due to the processes located within a geographical region, Europe (EU 27), in 2010. A robust regional inventory is a fundamental element for supporting the calculation of global factors, often resulting form extrapolation and upscaling from regional ones.

Methods The NFs for EU 27 in 2010 are based on extensive data collection and the application of extrapolation strategies for data gaps filling. The inventory is based on domestic emissions into air, water and soil and on resource extracted in EU, adopting a production-based approach. A hierarchy is developed for selection of data sources based on their robustness
\end{abstract}

Responsible editor: Jeroen Guinée

Electronic supplementary material The online version of this article (doi:10.1007/s11367-015-0958-8) contains supplementary material, which is available to authorized users.

Serenella Sala

serenella.sala@jrc.ec.europa.eu

1 European Commission, Joint Research Centre, Institute for Environment and Sustainability, Sustainability Assessment Unit, Via Enrico Fermi 2749 T.P. 270, 21027 Ispra, VA, Italy and quality. Data gap filling is based on several proxy indicators, specific for each impact category, capitalising existing statistics on pressure indicators (e.g. estimating ionising radiation emissions based on data of electricity production from nuclear power plants). To calculate NFs, the inventory is characterised using the International reference Life Cycle Data System (ILCD) Handbook (EC-JRC 2011a) midpoint indicators.

Results and discussion The resulting NFs present several added values compared to earlier normalisation exercises based on domestic inventories, namely more complete inventory, based on wide variety of sources; more comprehensive coverage of the flows within each impact category; overall evaluation of the robustness of the final figures; and robustness evaluation of the data sources. Contribution analysis shows that few flows $\left(\mathrm{NO}_{x}, \mathrm{SO}_{x}, \mathrm{NH}_{4}\right.$, etc.) are driving the impacts of several impact categories, and the choice of the data sources is particularly crucial, as this may lead to differences in the NFs. A qualitative uncertainty assessment is reported for each impact category. Besides, in order to test the robustness of the NFs, a sensitivity analysis on key choices and assumptions has been advocated.

Conclusion and outlook NFs may help identification of the relative magnitude of the impact. Nonetheless, several limitations still exist both at the inventory and at the impact assessment level, e.g., several inventory flows are not characterised as there is no characterisation factor available in current models. Those limitations should be clearly reported and understood by the users of normalisation factors in order to correctly interpret the results of their study as well as when regional NFs are used as basis for building global set of factor. The adoption of domestic NFs may, in fact, result in overestimating the relative magnitude of certain impacts, especially when those impacts are associated with traded goods from or outside the EU 27. Qualitative and quantitative 
assessment of uncertainties should be conducted from inventory to characterised results. Comprehensive testing is needed on the following: data sources, data mapping, regionalisation as well as models and system boundaries thereof. Strengths and limitations of the current study have implications also in other application contexts, as when indicators are needed to evaluate progress towards environmental policies goals. In fact, environmental impact indicators at regional scale often require data gap filling and estimation methodologies.

Keywords Domestic inventory · Emissions · ILCD . Integrated environmental assessment $\cdot$ Life cycle impact assessment $\cdot$ Normalisation factors

\section{Introduction}

According to ISO 14044 (ISO 2006), normalisation is an optional interpretation step of a complete life cycle assessment (LCA) study. Normalisation allows the LCA practitioner expressing results after characterisation using a common reference impact (Laurent et al. 2011a), and it may be particularly of help if results need to be communicated to decision makers in business and policy. In fact, using normalisation references, the relative magnitude of an impact may be related to other impacts in the life cycle of a product with a common unit and the relative magnitude of the contribution of the impact in one impact category may be compared with the magnitude of the contribution in another one. A reference region is commonly chosen to represent the background environmental burden related to all activities (e.g. economic, production activities) in that region under study. Normalisation values need to be regularly updated to be meaningful and to provide normalisation references that can be used by practitioners.

Results of several normalisation efforts are available to date. Just to name a few, Bare et al. 2006 developed other normalisation factors for US based on TRACI as life cycle impact assessment (LCIA) method. Sleeswijk et al. (2008) produced normalisation references for European and the global economic systems, considering 15 different impact categories for the year 2000. Laurent et al. (2011a) developed normalisation references for Europe and North America using USEtox (Rosenbaum et al. 2008) impact categories, considering 2002 as reference year for the European Union (EU), while 2002 and 2008 for North America. The inventory for Europe covers 38 countries from a number of databases and monitoring bodies across countries. In Laurent et al. (2011b), normalisation factors (NFs) are provided for the year 2004 adopting EDIP97 and EDIP2003 (Hauschild and Potting 2005) as LCIA methodology. Lautier et al. (2010) focused on the calculation of normalisation references for North America using the IMPACT2002+ (Jolliet et al. 2003) LCIA method. This work was also used as a basis for the modelling of North America by Laurent et al. (2011a).

Increasingly, the normalisation references are based on existing inventory of emissions and resource use (e.g. those collected by governmental bodies) as well as on proxy indicators for estimating missing flows. For example, Cucurachi et al. (2014) calculated a set of normalisation factors at European and global scale making use of proxy indicators and extrapolation strategies for estimating both European and global figures, focusing on toxicity.

The objective of the current study is the development of NFs for EU 27 for the year 2010, using data on domestic emissions in air, water and soil, and resource extraction characterised using the International reference Life Cycle Data System (ILCD) method for impact assessment (ECJRC 2011a). Those NFs could be used as reference for Product Environmental Footprint (PEF) (EU 2013) and be a basis for extrapolation and upscaling towards global NFs. A thorough understanding of the domestic normalised results is of upmost importance as this can be the basis for global factor extrapolation (e.g. Cucurachi et al. 2014) and for the calculation of factors with a consumption-based approach. The aim of the current paper is, therefore, to produce an extended inventory in which authoritative sources of data (e.g. from monitoring campaign and official reporting from governmental bodies) are coupled with proxy indicators, linking human interventions with emission estimates (e.g. estimating ionising radiation emissions electricity production from nuclear power plants or emission of pharmaceuticals from sales statistics) The domestic set of NFs is the result of an effort in extending the coverage of emissions and resource use, transparently reporting discrepancies, limitation and possible bias in the interpretation (e.g. as those indentified by Heijungs et al. 2007). It has to be noted that, beyond their use as NFs, the calculated figures allow an integrated assessment of environmental impacts of Europe in 2010 based on available data sources. Strengths and limitations of the current study have, then, implications also for other applications, such as data gap filling and estimation of potential environmental impacts.

Increasingly, it has been recognised that the quality of the reference data set depends on three factors: (i) data completeness of the inventory; (ii) the consistency between the system boundary of the inventory and the system boundary foreseen by the impact assessment model; (iii) and impact assessment models completeness and uncertainty. Therefore, an additional aim of this work is to assess the robustness of the calculated normalisation figures (Van Hoof et al. 2013).

The paper is organised as follows: in Section 2, we present the adopted methodology, the data sources and the critical aspects for each impact category; in Section 3, results are reported, indicating the substances contributing the most to each of the impact categories; the last section on discussion and conclusion presents an assessment of the robustness of the 
results, supporting the interpretation of the normalisation results and providing an outlook for future updates. Supporting information are available, including details on the following: the inventory, the modelling choices, the inventory database and the list of unmapped flows.

\section{Methodology}

The calculation of NFs for the PEF is based on a refinement and update of the 'Resource Life Cycle indicators' dataset developed by the European Commission-Joint Research Centre, used as inventory (Benini et al. 2014a). These indicators were developed within the Life Cycle Indicators framework (EC-JRC 2012) in the context of the EU Communication 'Roadmap to a resource efficient Europe' (CEC 2011). The aim of those indicators is to monitor the environmental impacts associated with European production and consumption, as well as waste management within the EU, by including also impacts from trade (imports and exports). In this work, we focus on the results of the domestic inventory as it has been identified as the currently most robust approach in a product comparison context, i.e. at micro scale (Benini et al. 2014b).

Several methodological choices for building the inventory and the normalisation references are made:

- The reference system is EU 27 in 2010. The inventory is based on an extensive data collection at country scale covering the years from 1990 to 2010. In Sala et al. 2014, details on time interpolation are reported for specific cases, e.g. when data were missing and an interpolation was needed.

- The inventory is covering domestic emissions into air, water and soil as well as resource extraction within EU 27 boundaries, entailing production and consumption elements (e.g. there are emissions of $\mathrm{CO}_{2}$ due to energy production as well as $\mathrm{CO}_{2}$ emissions due to use of private cars).

- The sources are selected following a hierarchical approach in order to guide the choice of the data when multiple possibilities were available. The overview of the data sources is reported in Tables 1 and 2, whereas the details on the hierarchical approach are described in the next section.

- Extrapolation and data filling strategies are adopted for completing the database because some data were missing. The details of the extrapolations are reported within each impact category. A full-fledged overview of methodologies for extrapolation is available in Sala et al. (2014).

- The ILCD recommended impact assessment models (ECJRC 2011a) are adopted for the life cycle impact assessment. The characterisation factors (CF) are used at midpoint (Sala et al. 2012), as currently used in the PEF.

\subsection{Domestic inventory and data sources}

The so-called domestic inventory of emissions into air, water and soil and resources extracted in 2010 in the EU 27 territory is mostly composed of datasets provided by international and European statistical agencies (Table 1). When relevant data are only partially available or completely missing in statistical datasets, several estimations based on proxy indicators are developed to fill the gaps. Extrapolation strategies and data gap filling estimation, specific for each impact category, are reported in Sala et al. (2014) along with their relative limitations.

In general, official statistics are preferred as they ensure a high degree of robustness and stakeholders acceptability, by means of the following: standardised protocols, metadata provision, recalculation procedures and quality assessment checks. Coverage of the EU 27 Member States, coverage of sectors responsible for the emissions, existence of a (international) review and quality assessment process and timing of the updates are also considered positive assets. A hierarchical approach is applied to the selection of the dataset to be used for building the domestic inventory when different sources were available for the same data, complementing the guidance on data selection proposed by Sleeswijk et al. (2008). In decreasing importance, we select the following:

- Officially reported data provided by EU and international bodies (Eurostat, FAO, OECD, BGS), based on agreed models, methods and standards, with documented metadata and periodical quality checks. Datasets already used in EU monitoring and policy making (e.g. IPCC, EEA based on EMEP, Eurostat, E-PRTR) and providing consistent time-series were preferred;

- Activity-based estimations, derived as 'activity data $x$ emission factor'. Activity data were taken from officially reported data; emission factors were based on scientific literature, grey literature (e.g. sectorial reports) and available life cycle inventories (LCIs);

- Statistical proxies (time, flows) when the correlation is statistically significant. When possible, consistency rules are applied (e.g. the sum of the estimated relative shares must sum-up to 1);

- Speculative assumption(s). Assumptions are based on reasonable correlation and/or cause-effect models, not statistically tested. Very often this strategy is used for filling-in punctual data gaps (e.g. figure available for 2009 and not for 2010, without evident underlying trend).

The domestic inventory is composed of raw data provided by third parties (e.g. national or international statistical offices) and data derived from estimations carried out in order to complement the available dataset with 
Table 1 Data sources used to compile the domestic inventory, for climate change; ozone depletion; particulate matter; photochemical ozone formation; terrestrial, freshwater and marine eutrophication; land use; resource depletion water; resource depletion mineral and fossil

\begin{tabular}{|c|c|c|c|}
\hline Impact category & Substance groups & Data sources & $\mathrm{Met}^{\mathrm{a}}$ \\
\hline \multirow[t]{5}{*}{ Climate change } & $\begin{array}{l}\mathrm{CO}_{2}, \mathrm{CH}_{4}, \mathrm{~N}_{2} \mathrm{O} \text { both from direct emissions } \\
\text { and those associated to LULUCF } \\
\text { (land use, land-use change and forestry) }\end{array}$ & - UNFCCC (2013) & $\mathrm{S}$ \\
\hline & HFCs, PFCs and SF6 & - UNFCCC (2013) & \\
\hline & Other substances $^{\mathrm{b}}$ & $\begin{array}{l}\text { - Total NMVOC per sector from: CORINAIR/EEA } \\
\text { (2007, 2009);EMEP/CEIP (2013a) for sector } \\
\text { activity modelling; speciation per sectors } \\
\text { (Laurent and Hauschild 2014) }\end{array}$ & A \\
\hline & HCFC-141b, HCFC-142b & - EDGARv4.2 (EC-JRC \& PBL 2011) & \\
\hline & 1,1,1-Trichloroethane & - E-PRTR database (EEA 2013a) & \\
\hline \multirow[t]{3}{*}{ Ozone depletion } & CFCs, HCFCs, etc. & $\begin{array}{l}\text { - Total NMVOC per sector from: CORINAIR/EEA } \\
\text { (2007, 2009);EMEP/CEIP (2013a) 'EMEP_reported' } \\
\text { for sector activity modelling; speciation per sectors } \\
\text { (Laurent and Hauschild 2014) }\end{array}$ & A, B \\
\hline & HCFC-141b, HCFC-142b & - EDGARv4.2 (EC-JRC \& PBL 2011) & \\
\hline & 1,1,1-Trichloroethane & - E-PRTR database (EEA 2013a) & \\
\hline \multirow[t]{3}{*}{$\begin{array}{l}\text { Particulate matter/ } \\
\text { respiratory inorganics }\end{array}$} & $\begin{array}{l}\mathrm{CO}, \mathrm{NO}_{x}\left(\text { as } \mathrm{NO}_{2}\right) \\
\mathrm{SO}_{2}, \mathrm{NH}_{3}\end{array}$ & $\begin{array}{l}\text { - UNFCCC (2013) } \\
\text { - EMEP/CEIP (2013b) - 'EMEP_modeled' dataset }\end{array}$ & $\mathrm{T} 1, \mathrm{~T} 4$ \\
\hline & $\mathrm{PM}_{10}, \mathrm{PM}_{2.5}$ & - EEA (2013c) & \\
\hline & $\mathrm{PM}_{0.1}$ & - EDGARv4.2 (EC-JRC \& PBL 2011) & \\
\hline \multirow[t]{2}{*}{$\begin{array}{l}\text { Photochemical } \\
\text { ozone formation }\end{array}$} & NMVOC & $\begin{array}{l}\text { - Total NMVOC per sector from: CORINAIR/EEA } \\
\text { (2007, 2009);EMEP/CEIP (2013a) for sector activity } \\
\text { modelling; speciation per sectors } \\
\text { (Laurent and Hauschild 2014) }\end{array}$ & A \\
\hline & $\begin{array}{l}\mathrm{NO}_{x}\left(\text { as } \mathrm{NO}_{2}\right) \\
\mathrm{SO}_{2}\end{array}$ & $\begin{array}{l}\text { - UNFCCC (2013) } \\
\text { - EMEP/CEIP (2013b)_EEMEP_modeled' dataset }\end{array}$ & $\mathrm{T} 1, \mathrm{~T} 2$ \\
\hline Acidification & $\begin{array}{l}\mathrm{NO}_{x}\left(\text { as } \mathrm{NO}_{2}\right) \\
\mathrm{SO}_{2}, \mathrm{NH}_{3}\end{array}$ & $\begin{array}{l}\text { - UNFCCC (2013) } \\
\text { - EMEP/CEIP (2013b)_EMEP_modeled dataset }\end{array}$ & $\mathrm{T} 1, \mathrm{~T} 2$ \\
\hline Terrestrial eutrophication & $\begin{array}{l}\left.\mathrm{NO}_{x} \text { (as } \mathrm{NO}_{2}\right) \\
\mathrm{NH}_{3}\end{array}$ & $\begin{array}{l}\text { - UNFCCC (2013) } \\
\text { - EMEP/CEIP (2013b) - 'EMEP_modeled' dataset }\end{array}$ & $\mathrm{T} 1, \mathrm{~T} 2$ \\
\hline Freshwater eutrophication & $\begin{array}{l}\text { Phosphorous (total) to soil and water, } \\
\text { from agriculture }\end{array}$ & $\begin{array}{l}\text { - Eurostat (2013g) for phosphorous input and output data } \\
\text { - UNFCCC (2013) for nitrogen input } \\
\text { - FAOstat (2013b) for cultivated cereal surfaces } \\
\text { - Bouwman et al. (2009) } 10 \% \text { loss of P to water } \\
\text { as global average } \\
\text { - Removal efficiency of phosphorous Van Drecht } \\
\text { et al (2009) } \\
\text { - Use of laundry and dishwater detergents, (RPA 2006) } \\
\text { - Fraction of P-free laundry detergent (RPA 2006) } \\
\text { - \% of people connected to wastewater treatment OECD } \\
\text { (2013a), Eurostat (2013h) }\end{array}$ & I \\
\hline \multirow[t]{3}{*}{ Marine eutrophication } & $\begin{array}{l}\mathrm{NO}_{\mathrm{x}}\left(\text { as } \mathrm{NO}_{2}\right) \\
\mathrm{NH}_{3}\end{array}$ & $\begin{array}{l}\text { - UNFCCC (2013) } \\
\text { - EMEP/CEIP (2013b) - 'EMEP_modeled' dataset }\end{array}$ & $\mathrm{T} 1, \mathrm{~T} 2$ \\
\hline & Nitrogen (total) to water, from agriculture & $\begin{array}{l}\text { - Ntot input data, losses to water and to air, synthetic } \\
\text { fertilisers, manure UNFCCC (2013) } \\
\text { - N output based on ratios (by country, by year) between } \\
\text { input and output by Eurostat ( } 2013 \mathrm{~g}) \text {, multiplied to } \\
\text { inputs from UNFCCC (2013) }\end{array}$ & I \\
\hline & $\begin{array}{l}\text { Nitrogen (total) to soil and water, } \\
\text { from sewages }\end{array}$ & $\begin{array}{l}\text { - Protein intake, FAOstat (2013f) } \\
\text { - Removal efficiency of nitrogen (Van Drecht et al 2009) } \\
\text { - Percentage of people connected to WWTP OECD (2013a) } \\
\text { and Eurostat (2013h) }\end{array}$ & \\
\hline Land use & $\begin{array}{l}\text { 'Land occupation' and 'land transformation': } \\
\text { forest, cropland, grassland, settlements, } \\
\text { unspecified }\end{array}$ & $\begin{array}{l}\text { - UNFCCC (2013) national inventories } \\
\text { - Corine Land Cover (EEA 2012) for CY and MT }\end{array}$ & $\mathrm{R}$ \\
\hline Resource depletion, water & Gross freshwater abstraction & - Eurostat (2013i); OECD (2013b); FAO-Aquastat (2013) & $\mathrm{J}$ \\
\hline
\end{tabular}


Table 1 (continued)

\begin{tabular}{lll}
\hline Impact category & Substance groups & Data sources $^{\text {Met }^{\mathrm{a}}}$ \\
\hline $\begin{array}{l}\text { Resource depletion, } \\
\text { minerals and fossils }\end{array}$ & Metals & - British Geological Survey_BGS (1995, 2000, 2002, 2012) \\
& & K2, K3 \\
& & - Raw Material Group RMG (2013) \\
& Minerals & - EC (2014) \\
& Energy carriers & - PRODCOM (PRODCOM/Eurostat, 2013) \\
& - Eurostat (20131, m, n, o, p, q) \\
\hline
\end{tabular}

${ }^{\text {a }}$ Method for extrapolation as reported in Sala et al. 2014

${ }^{\mathrm{b}}$ Including 1,1,2-trichloro-1,2,2-trifluoroethane, methylene chloride, chloroform, tetrachloromethane, chlorodifluoromethane, dichlorofluoromethane, CFCs and dichloromethane

additional information (following the hierarchy from 2 to 4). An example of raw data is the emission of $x$ tons of $\mathrm{CO}_{2}$ occurring in a given country for a given year, as reported by the dataset of UNFCCC (2013), which is the international body deputed to the collection of data on greenhouse gas (GHGs) emissions. When more than one international or EU statistical agency collected datasets related to the same emission of a given pollutant, additional rules were used to provide a justification to the selection. For instance, for what concerns $\mathrm{NO}_{x}, \mathrm{NH}_{3}, \mathrm{SO}_{x}$ and $\mathrm{CO}$ the priority in selecting the data sources is set as follows: UNFCCC (2013)> EMEP_modeled (EMEP/CEIP, 2013b) $>$ EMEP_reported (EMEP/CEIP 2013a) > EDGARv4.2 (EC-JRC \& PBL 2011). This is coherent to decisions by a team of experts from EC-JRC, PBL, UNFCCC and EMEP, as reported in EC-JRC (2011b) on the basis of ECE (2010). The data sources for those substances are then as follows: UNFCCC for $\mathrm{CO}$ and $\mathrm{NO}_{x}$ (reported as $\mathrm{NO}_{2}$ ) and the EMEP/CEIP database for $\mathrm{NH}_{3}$ and $\mathrm{SO}_{x}$ (reported as $\left.\mathrm{SO}_{2}\right)(\mathrm{EMEP} / \mathrm{CEIP} 2013 \mathrm{~b})$. The choice of the dataset is based on the following: coverage of the EU 27 Member States; coverage of sectors responsible for the emissions; existence of a (international) review and quality assessment process; and timing of the updates. The UNFCCC is a trusted source of data reported by countries and reviewed by an international scientific panel. EMEP provides two types of datasets: national inventories and data used in EMEP models. The latter dataset is an aggregated and data gap filled version of the former; this version is used when available, on the basis of a systematic quality and review process. EDGAR v4.2 is a bottom-up modelling exercise based on activity data and emission factors from time periods up to 2008 (as a result of the fast-track expansion of EDGAR v4.1). It has the advantage of being coherent among the different Member States. However, there is no periodical review and update process. Therefore, the priority in selecting the data sources has been set as follows: UNFCCC > EMEP_model > EMEP_report $>$ EDGARv4.2 in line with decisions from a team of experts from EC-JRC, PBL, UNFCCC and
EMEP as reported in EC-JRC (2012d) on the basis of ECE (2010).

The amount of nitrogen (total) discharged into freshwater bodies from wastewater treatment plants is an example of estimated inventory data. This value is estimated for each EU country by applying the following: (i) figures from the literature (Van Drecht et al. 2009); (ii) data from Eurostat (statistics on population connection to wastewater treatments plants, by level of treatment); and (iii) data from FAOstat (FAOstat 2013f, statistics on yearly average intake of proteins per EU inhabitant). An in-depth presentation of the methodologies developed to estimate missing substances and punctual values is briefly mentioned in each impact category and extensively reported in Sala et al. (2014).

Additionally, several assumptions are also needed to map territorial statistics data into ILCD-consistent elementary flows so to allow for their compatibility with an ILCD compliant LCA calculation.

Even if data are reported by country within the inventory, default (non-country-specific) CFs are used for calculating NFs. Moreover, notwithstanding the elementary flows descriptions identify specific emissions' details (e.g. emission into air, 'high stack'), the default CFs for emission to air 'unspecified' was chosen. This was mainly due to the aggregated nature of statistical data, hampering higher level of discrimination in the emission typologies.

In Table 1 and Table 2, the list of data sources and estimation methods by group of substance are presented with their relation to each impact category. In the supporting information (SI), an extended version of the tables is reported, including the added value compared to previous normalisation inventories (e.g. regarding the completeness of the coverage, the development of impact category-specific proxies, the evaluation of uncertainties associated to the source and the impact assessment methods). In Benini et al. (2014b), a specific assessment of the discrepancies between this inventory and previous sets has been carried out. The two normalisation sets, hereinafter reported as $\mathrm{CML}_{2000}$ (2015) and $\mathrm{ReCiPe}_{2000}$ (2015), are both based on Sleeswijk et al. 2008 with some differences in the inventory and different impact assessment models. 
Table 2 Data sources used to compile the domestic inventory, for toxicity-related impact categories and ionising radiation

\begin{tabular}{|c|c|c|c|}
\hline Impact category & Substance groups & Data sources & $\mathrm{Met}^{\mathrm{a}}$ \\
\hline \multirow{12}{*}{$\begin{array}{l}\text { Human toxicity } \\
\text { (cancer, non-cancer) } \\
\text { and ecotoxicity }\end{array}$} & \multicolumn{3}{|l|}{ Air emissions } \\
\hline & Heavy metals (HM) & - EMEP/CEIP (2013a) ‘EMEP_reported’ & $\mathrm{C}$ \\
\hline & $\begin{array}{l}\text { Organics (non-NMVOC): } \\
\text { e.g. dioxins, PAH, } \\
\text { HCB, etc. }\end{array}$ & $\begin{array}{l}\text { - EMEP/CEIP (2013a) ‘EMEP_reported’, } \\
\text { - E-PRTR (EEA 2013a) }\end{array}$ & \\
\hline & NMVOC & $\begin{array}{l}\text { - Total NMVOC per sector from: CORINAIR/ } \\
\text { EEA (2007; 2009);EMEP/CEIP (2013a) } \\
\text { for sector activity modelling; speciation } \\
\text { per sectors (Laurent and Hauschild 2014) }\end{array}$ & \\
\hline & \multicolumn{2}{|l|}{ Water emissions } & \multirow[t]{3}{*}{$D$} \\
\hline & Industrial releases of $\mathrm{HM}+$ organics & $\begin{array}{l}\text { - E-PRTR (EEA 2013a) } \\
\text { - Waterbase (EEA 2013b) } \\
\text { - Eurostat (2013a) }\end{array}$ & \\
\hline & Urban WWTP (HM + organics) & $\begin{array}{l}\text { - Waterbase (EEA 2013b), OECD (2013a), } \\
\text { Eurostat (2013b) }\end{array}$ & \\
\hline & \multicolumn{3}{|l|}{ Soil emission } \\
\hline & $\begin{array}{l}\text { Industrial releases (HM, POPs) } \\
\text { Sewage sludge (containing } \\
\quad \text { organics and metals) }\end{array}$ & $\begin{array}{l}\text { - E-PRTR (EEA 2013a) } \\
\text { - Usage EEA (2013b) and Eurostat (2013c) } \\
\text { - EC (2010) for heavy metal composition } \\
\text { - EC (2001) for dioxins }\end{array}$ & \multirow[t]{2}{*}{$\mathrm{E}$} \\
\hline & Manure & $\begin{array}{l}\text { - FAOstat (2013a), Amlinger et al. (2004), } \\
\text { Chambers et al. (2001) }\end{array}$ & \\
\hline & \multicolumn{3}{|l|}{ Pesticides } \\
\hline & Active ingredients (AI) breakdown & $\begin{array}{l}\text { - Pesticide usage data: FAOstat (2013d; 2013e) } \\
\text { (F, H, I, O + chemical classes) + Eurostat (2013f) } \\
\text { for second check } \\
\text { - Eurostat (2013d) for crop harvested areas; } \\
\text { FAOstat (2013b) } \\
\text { - FAOstat (2013c) for organic areas }\end{array}$ & $\mathrm{F}$ \\
\hline \multirow[t]{5}{*}{ Ionising radiations } & $\begin{array}{l}\text { Emissions of radionuclides to air } \\
\text { and water from energy production } \\
\text { (nuclear and coal) }\end{array}$ & $\begin{array}{l}\text { - UNSCEAR data on emissions factors (2008) } \\
\text { for }{ }^{14} \mathrm{C},{ }^{3} \mathrm{H},{ }^{131} \mathrm{I} \text {; } \\
\text { - Nuclear energy production (Eurostat 20131, m) } \\
\text { - Ecoinvent } 3.01 \text { (Weidema et al. 2013) } \\
\text { - OSPAR (2013a) }\end{array}$ & M1 \\
\hline & $\begin{array}{l}\text { Emissions of radionuclides to air } \\
\text { and water from nuclear spent-fuel } \\
\text { reprocessing }\end{array}$ & $\begin{array}{l}\text { - UNSCEAR data (2008) on emissions emission } \\
\text { factors for }{ }^{3} \mathrm{H},{ }^{14} \mathrm{C},{ }^{60} \mathrm{Co},{ }^{90} \mathrm{Sr},{ }^{99} \mathrm{Tc},{ }^{129} \mathrm{I},{ }^{106} \mathrm{Ru} \text {, } \\
{ }^{137} \mathrm{Cs} \text { and }{ }^{241} \mathrm{Pu} \\
\text { - Spent-fuel reprocessing statistics are from the International } \\
\text { Panel on Fissile Materials (IPFM) (Forwood 2008; } \\
\text { Schneider and Marignac 2008) }\end{array}$ & M2 \\
\hline & $\begin{array}{l}\text { Discharge of radionuclides from non-nuclear } \\
\text { activities (radio-chemicals production } \\
\text { and research facilities) }\end{array}$ & $\begin{array}{l}\text { - OSPAR Commission database (OSPAR 2013b) for } \\
\text { radio-chemicals production and research facilities }\end{array}$ & $\mathrm{N}$ \\
\hline & $\begin{array}{l}\text { Discharge of radionuclides from oil } \\
\text { and gas industry }\end{array}$ & $\begin{array}{l}\text { - OSPAR Commission database (OSPAR 2013c) } \\
\text { - Overall oil production figures (Eurostat 2013r) }\end{array}$ & $\mathrm{N}$ \\
\hline & $\begin{array}{l}\text { Emissions to air and water from the } \\
\text { end-of-life scenario of gypsum boards }\end{array}$ & $\begin{array}{l}\text { - Ecoinvent (v 3.01) unit processes (Weidema et al. 2013); } \\
\text { - PRODCOM data (PRODCOM/Eurostat 2013) }\end{array}$ & $\mathrm{O}$ \\
\hline
\end{tabular}

${ }^{\text {a }}$ Method for extrapolation as reported in Sala et al. 2014

\subsection{Robustness assessment of the resulting NFs}

For each impact category, three elements were assessed for determining the quality and reliability of NFs, namely coverage completeness, robustness of the inventory and robustness of the impact assessment model.
- The coverage completeness assesses the availability of emissions and resources extraction in the inventory. The estimate is based on the extent to which the inventory data are available compared to available flows in ILCD for the specific impact category. A table detailing the number of elementary flows having a characterisation factors in ILCD, and the 
coverage in the inventory for the normalisation has been added in the Electronic Supplementary Material (Table SI2). The resulting scores are as follows: I-good; II-fair; III-poor depending on number of flows available.

- The robustness of the inventory is assessed based on data quality and robustness of the extrapolation strategy adopted to populate missing flows. In Sala et al. (2014), details on statistical and uncertainty analysis of extrapolation strategies are reported. Three levels are assigned: level I, published datasets from officially formalised data sources - subjected to a quality assurance procedureand limited use of extrapolation method $(<20 \%$ of the impact derived from extrapolation); level II, unpublished datasets and/or use of extrapolation methods for more than $20 \%$ but less than $80 \%$ of the impact; level III, use of extrapolation methods for more than $80 \%$ of the impact.

- The robustness of the impact assessment methods is reported following the ILCD classification (EC-JRC 2011a): level I corresponds to a 'recommended and satisfactory' method, level II is 'recommended but in need of some improvement' and level III is 'recommended but to be applied with caution'.

This evaluation is intended to make practitioners aware of the uncertainty behind the calculated normalisation factors, particularly important for some impact categories. This robustness assessment refers to the normalisation references as result of the described choices and assumptions.

\section{Results and discussion}

The NFs for the EU 27 domestic inventory in 2010 are reported in Table 3, along with the indicators used for calculations and an overall robustness assessment of the factors. It builds upon the inventory characterised using ILCD method (ECJRC 2011a). In SI, a spreadsheet is available containing the ILCD recommended characterisation factors, the emission and extraction totals (for the EU 27), and the resulting normalisation factors. NFs per person are calculated using Eurostat data on EU 27 population in 2010 (Eurostat 2013a, b, c, d, e, f, g, h, i, j, k, l, m, n, o, p).

In the following sections, we report for each impact category: (i) the data source; (ii) the extrapolation method adopted and the related sources; (iii) the coverage of the flows in the inventory with respect to the available flows in ILCD; (iv) the contribution analysis to the final figure; and (iv) the main drivers of uncertainty.

The added value of this inventory and NFs if compared to previous ones is reported in (SI). A systematic numerical comparison of those figures is reported in Benini et al. (2014b), including NFs from $\mathrm{CML}_{2000}$ and the inventory based on the current EC-JRC methodology for 3 years (2000, 2006 and 2010).

\subsection{Climate change (CC)}

Air emissions contributing to climate change where mainly taken from the United Nations Framework Convention on Climate Change (UNFCCC 2013). Additionally, data on non-methane volatile organic compounds (NMVOC) were estimated through a methodology for the breakdown of NMVOC substances at sector level (Laurent and Hauschild 2014), building on data from the European Monitoring and Evaluation Programme (EMEP) as reported by the Centre on Emission Inventories and Projections (CEIP) (EMEP/CEIP 2013a). 'Officially reported emission data' were used and combined with speciation profiles (i.e. breakdown of NMVOC single substances) to each activity sector. This method combines available speciation profiles, i.e. distributions of substances emitted per type of sources, and sectorial NMVOC information to reach country-specific, sector-specific emission profiles. Speciation profiles were retrieved from different literature sources as well as from CORINAIR emission inventory reports $(2007,2009)$.

Emissions of hydrofluorocarbons (HCFC-141b and $\mathrm{HCFC} 142 \mathrm{~b}$ ) were retrieved from the EDGAR database (ECJRC \& PBL 2011) and emissions of 1,1,1-trichloroethane were separately retrieved from the E-PRTR database (EEA 2013a).

The inventory covers 23 substances out of 101 for which a $\mathrm{CF}$ is available in ILCD. Three substances dominate the overall impact, contributing to $98 \%$ of the total, respectively $\mathrm{CO}_{2}$ (79\%) $\mathrm{CH}_{4}(11 \%)$ and $\mathrm{N}_{2} \mathrm{O}(7 \%)$.

Uncertainties related to UNFCCC (2013) data arise from the different tiered approaches for the compilation of the inventories by countries. Regarding NMVOC, data robustness is limited by the high heterogeneity among data sources, mixing reporting datasets, e.g. EMEP/CEIP (2013a), EPRTR, (EEA 2013a) and bottom-up modelling exercises (EDGAR). In addition, EMEP/CEIP (2013a) present data gaps for few countries, which were filled through extrapolations (see Sala et al. 2014).

The NFs for climate change are likely to be slightly underestimated due to missing data for some chloro fluoro carbons (CFCs). Additionally, the UNFCCC dataset lacks disaggregated data for some substances (PFCs and HFCs). Hence, an average characterisation factor has been applied for the each group separately, namely PFCs and HFCs (Benini et al. 2014b).

\subsection{Ozone depletion (OD)}

Air emissions contributing to OD have been mainly estimated on the basis of NMVOC emission data, as explained above (Laurent and Hauschild 2014).

The same sources as for climate change were used also for emissions of hydrofluorocarbons (HCFC-141b and 
Table 3 Normalisation factor for EU 27 in 2010 for domestic emission and resource extraction, the scoring is given from I- highest to III—-lowest

\begin{tabular}{|c|c|c|c|c|c|c|c|}
\hline Impact category & Unit & $\begin{array}{l}\text { NFs for } \\
\text { EU } 27\end{array}$ & $\begin{array}{l}\text { NFs per } \\
\text { person }\end{array}$ & $\begin{array}{l}\text { Coverage } \\
\text { completeness }^{\mathrm{a}}\end{array}$ & $\begin{array}{l}\text { Robustness } \\
\text { inventory }\end{array}$ & $\begin{array}{l}\text { Robustness impact } \\
\text { assessment }^{\mathrm{c}}\end{array}$ & $\begin{array}{l}\text { Overall } \\
\text { robustness }\end{array}$ \\
\hline Climate change & $\mathrm{kg} \mathrm{CO}_{2}$ eq & $4.60 \mathrm{E}+12$ & $9.22 \mathrm{E}+03$ & $\mathrm{I} / \mathrm{II}$ & I & I & High \\
\hline Ozone depletion & kg CFC-11 eq & $1.08 \mathrm{E}+07$ & $2.16 \mathrm{E}-02$ & II & III & I & Medium \\
\hline Particulate matter & $\mathrm{kg} \mathrm{PM}_{2.5}$ eq & $1.90 \mathrm{E}+09$ & $3.80 \mathrm{E}+00$ & I & $\mathrm{I} / \mathrm{II}$ & I & High \\
\hline Photochemical ozone formation & $\mathrm{kg}$ NMVOC eq & $1.58 \mathrm{E}+10$ & $3.17 \mathrm{E}+01$ & I & II & II & Medium \\
\hline Acidification & $\mathrm{mol} \mathrm{H}^{+}$eq & $2.36 \mathrm{E}+10$ & $4.3 \mathrm{E}+01$ & I & II & II & Medium \\
\hline Terrestrial eutrophication & mol $\mathrm{N}$ eq & $8.76 \mathrm{E}+10$ & $1.76 \mathrm{E}+02$ & $\mathrm{I} / \mathrm{II}$ & I & II & Medium \\
\hline Freshwater eutrophication & $\mathrm{kg} P$ eq & $7.41 \mathrm{E}+08$ & $1.48 \mathrm{E}+00$ & $\mathrm{I} / \mathrm{II}$ & II/III & II & Medium to low \\
\hline Marine eutrophication & $\mathrm{kg} \mathrm{N}$ eq & $8.44 \mathrm{E}+09$ & $1.69 \mathrm{E}+01$ & II & II & II & Medium to low \\
\hline Land use & $\mathrm{kg} \mathrm{C}$ deficit & $3.78 \mathrm{E}+13$ & $7.58 \mathrm{E}+04$ & II/III & II & III & Low \\
\hline Resource depletion water & $\mathrm{m}^{3}$ water eq & $4.06 \mathrm{E}+10$ & $8.14 \mathrm{E}+01$ & III & II & III & Low \\
\hline $\begin{array}{l}\text { Mineral, fossil and renewable } \\
\text { resource depletion }\end{array}$ & $\mathrm{kg} \mathrm{Sb}$ eq & $5.03 \mathrm{E}+07$ & $1.01 \mathrm{E}-01$ & II & II & II & Medium \\
\hline Human toxicity cancer & CTUh & $1.88 \mathrm{E}+04$ & $3.77 \mathrm{E}-05$ & III & III & II/III & Low \\
\hline Human toxicity non-cancer & CTUh & $2.69 \mathrm{E}+05$ & $5.39 \mathrm{E}-04$ & II & III & II/III & Low \\
\hline Freshwater ecotoxicity & CTUe & $4.46 \mathrm{E}+12$ & $8.94 \mathrm{E}+03$ & III & III & II/III & Low \\
\hline Ionising radiations & $\mathrm{kBq} \mathrm{U}_{235} \mathrm{eq}$ & $5.64 \mathrm{E}+11$ & $1.13 \mathrm{E}+03$ & I & II & II & Medium \\
\hline
\end{tabular}

${ }^{\text {a }}$ Completeness of the dataset used for the inventory. Coverage estimate based on the extent to which the inventory data are available compared to available flows in ILCD for the specific impact category. A detailed table is reported in SI. Double values reflect the fact that the coverage is depending on completeness for different compartments

${ }^{\mathrm{b}}$ Based on data quality and robustness of the extrapolation strategy adopted

${ }^{\mathrm{c}}$ Robustness of the impact assessment methods, as assessed in ILCD evaluation of methods EC-JRC 2011a

HCFC142b) (EC-JRC \& PBL 2011) and 1,1,1-trichloroethane (EEA 2013a).

Inventory data are available for 7 flows out of 23 for which there is a CF in the ILCD.

The normalisation factor for this impact category is dominated by two flows: CFC-12 (55 \%) and CFC-11 (39\%).

In 2010 the facilities located in EU 27 emitted overall $7.63 \mathrm{E}+04 \mathrm{~kg}$ of CFCs according to E-PRTR (EEA 2013a), However, according to our inventory, which is based on extrapolations, the amount of CFCs released to air is equal to $1.04 \mathrm{E}+07 \mathrm{~kg}$. As reported by the EEA (2013a), E-PRTR offers only a partial coverage of emissions, as only facilities above fixed thresholds are obliged to report such emission data. Moreover, as reported in the E-PRTR website, the query that relates to CFC is affected by confidentiality issues which may affect the results as well. Nonetheless, the values reported for the HCFCs in E-PRTR are slightly higher than those estimated in the inventory.

According to Fahey and Hegglin (2011), who report the global distribution of anthropogenic OD substances entering the stratosphere in 2008, it can be estimated that more than $90 \%$ of the chlorine source emissions are covered by our present inventory (e.g. CFC-12, CFC-11, carbon tetrachloride, HCFC-22, CFC-113). On the other hand, a gap lies with the unreported emissions of bromine source gases (e.g. halon1211, halon-1301, methyl bromide). Based on expert's knowledge, about $70 \%$ of the OD potential is expected to be covered by the currently defined emission inventory. This information has been used to estimate the qualitative uncertainties associated to the inventory. Hence, uncertainties in the estimation are considered to be quite high, mostly depending on the following points: brominated substances are not accounted for in the inventory; there is high heterogeneity among data sources, as the inventory combines different datasets (EMEP/CEIP, E-PRTR) and bottom-up modelling exercises (EDGAR), which are developed for different purposes and applications. Moreover, figures from E-PRTR are likely to be underestimated as reporting obligations apply only for above activity thresholds.

\subsection{Particulate matter and respiratory inorganics (RI)}

The inventory for $\mathrm{RI}$ is built using the following data sources: UNFCCC (2013) for $\mathrm{NO}_{x}$ (reported as $\mathrm{NO}_{2}$ ) and $\mathrm{CO}$; EMEP/CEIP (2013b) database 'modeled' for $\mathrm{SO}_{x}$ (reported as $\mathrm{SO}_{2}$ ) and $\mathrm{NH}_{3}$; EEA (2013c) for $\mathrm{PM}_{2.5}$ and $\mathrm{PM}_{10}$. The flows of $\mathrm{NO}_{x}$ and $\mathrm{SO}_{x}$ reported in the original statistics as $\mathrm{NO}_{2}$ and $\mathrm{SO}_{2}$ were mapped into the following ILCD flows: nitrogen dioxide $\left(\mathrm{NO}_{2}\right)$ and sulphur dioxide $\left(\mathrm{SO}_{2}\right)$. The respective ILCD characterisation factors were used for calculating the midpoint impact category indicator although the combination of nitrogen (or sulphur) monoxide and nitrogen (or sulphur) dioxide of the underlying data is unknown. Data on both $\mathrm{PM}_{10}$ and $\mathrm{PM}_{2.5}$ were retrieved from EEA. $\mathrm{PM}_{2.5}$ chosen 
as the underlying impact assessment method (Humbert 2009) assumes $\mathrm{PM}_{2.5}$ to be the only responsible for the health impacts due to $\mathrm{PM}_{10}$ exposure, so to avoid double counting (Humbert 2014).

Inventory data are available for six flows out of nine for which there is a CF in the ILCD.

The highest contributor to this impact category is $\mathrm{PM}_{2.5}$, covering $69 \%$ of the overall impact. $\mathrm{SO}_{2}, \mathrm{NH}_{3}$ and $\mathrm{NO}_{2}$ summed together cover $30.5 \%$ of the impact and a minor role is exerted by $\mathrm{CO}(0.5 \%)$. Manure and fertilisers are indirectly accounted for as $\mathrm{NH}_{3}$ emissions.

The main uncertainties at the inventory level are related to different figures reported in available international emission inventories for $\mathrm{NO}_{x}, \mathrm{SO}$. and $\mathrm{NH}_{3}$, namely UNFCCC (2013), EMEP/CEIP (2013b), EEA (2013c), EDGARv4.2 (EC-JRC \& PBL 2011), GAINS by IIASA (2013) and Rafaj et al. (2014).

On top of the above discrepancies for $\mathrm{SO}_{x}, \mathrm{NH}_{3}$ and $\mathrm{NO}_{x}$, the current estimation of $\mathrm{PM}_{10}$ and $\mathrm{PM}_{2.5}$ emissions is 27 to $25 \%$ lower than the figures reported in the EDGARv4.2 database.

However, because of the review and quality assessment process which the retrieved datasets are subjected to, this source of information is considered to be reliable enough for being used as basis for the NFs. For what concerns the impact assessment, the most sensitive aspect is the mutually exclusive choice between $\mathrm{PM}_{10}$ and $\mathrm{PM}_{2.5}$ to be included within the LCIA phase.

\subsection{Photochemical ozone formation (POF)}

The flows that contribute to POF are derived from different sources, adopting the hierarchical approach presented in the methodological section.

Inventory data are available for 89 flows out of 132 for which there is a CF in the ILCD.

The NF for POF presents a relative contribution as follows: $58 \% \mathrm{NO}_{2}$, followed by $7 \% \mathrm{CO}, 4 \% \mathrm{~m}$-xylene, $3 \% \mathrm{SO}_{2}$ and $3 \%$ ethylene. Other compounds, mostly NMVOC, contribute up to $26 \%$ of the total. It has to be noted that a generic characterisation factor for NMVOC exists. However, the overall impact of those substances is lower when using the flows resulting from an emissions breakdown.

\subsection{Acidification (AC)}

The emissions into air for the inventory of acidifying substances in 2010 are based on UNFCCC (2013) for $\mathrm{NO}_{x}$ and EMEP/CEIP (2013b) for $\mathrm{SO}_{x}$ and $\mathrm{NH}_{3}$. The emission into air includes those derived from volatilisation of $\mathrm{NH}_{3}$ related to application of fertilisers and manure to soil.

Inventory data are available for three flows out of six for which there is a CF in the ILCD.
In particular, the missing flows are as follows: nitrogen monoxide, sulphur trioxide and sulphur oxides. This is due to the fact that no statistics on sulphur trioxide were available and to the fact that $\mathrm{NO}_{x}$ and $\mathrm{SO}_{x}$ were mapped as $\mathrm{NO}_{2}$ and $\mathrm{SO}_{2}$, as the actual ratio $\mathrm{NO} / \mathrm{NO}_{2}$ is very specific of the combustion process that generates these emissions and such value is usually not reported in national inventories. It is relevant to note that the ILCD does not contain characterisation factors for acidifying substances which are emitted to soil, such as manure and fertilisers. Other emission inventories (e.g. $\mathrm{ReCiPe}_{2000}$ ) however do include these.

Within the 2010 inventory, only three flows contribute to acidification: ammonia, nitrogen dioxide and sulphur dioxide, covering, respectively, 46,29 and $25 \%$ of the impact category.

Uncertainties affecting this normalisation factor may stem from both the inventory data and the characterisation factors. For 2010, the uncertainty may be associated to the source selection show that is UNFCC, EMEP modelled, EEA consolidated data and EDGAR 4.2. Further uncertainty may be associated with the choice of characterisation factors for $\mathrm{NO}_{x}$ and $\mathrm{SO}_{x}$ that may stem from applying a different assumption than mapping into $\mathrm{NO}_{2}$ and $\mathrm{SO}_{2}$.

\subsection{Eutrophication terrestrial (ET)}

The flows that contribute to terrestrial eutrophication are $\mathrm{NO}_{x}$ and $\mathrm{NH}_{3}$ emitted to air. The data sources are UNFCCC (2013) for $\mathrm{NO}_{x}$ (reported as $\mathrm{NO}_{2}$ ) and the EMEP/CEIP (2013b) 'modelled' database for $\mathrm{NH}_{3}$. The flows of $\mathrm{NO}_{x}$ as retrieved from the statistics were mapped into the respective ILCD flow, i.e. nitrogen dioxide $\left(\mathrm{NO}_{2}\right)$; as a consequence, the corresponding characterisation factor was used for calculating the midpoint impact indicator.

Inventory data were available for two $\left(\mathrm{NO}_{x}\right.$ and $\mathrm{NH}_{3}$ to air) flows out of six for which there is a CF in the ILCD. The underpinning model (Seppälä et al. 2006) provides characterisation factors due to deposition from air and not for emissions into soil. Overall, emissions of $\mathrm{NH}_{3}$ to air contribute to $55 \%$ of the impacts and the remaining $45 \%$ is from $\mathrm{NO}_{x}$ to air. Also in this case, uncertainties are mainly related to the mapping of $\mathrm{NO}_{x}$ and $\mathrm{NH}_{3}$.

\subsection{Eutrophication freshwater (EF) and eutrophication marine (EM)}

The emissions to water leading to eutrophication, both nitrogen (Ntot) and phosphorus (Ptot), are estimated on the basis of the methodology developed by Van Drecht et al. $(2003,2009)$. The key data sources underlying such estimates are Eurostat (2013h), UNFCCC (2013) and Faostat (2013b, f).

The inventory for freshwater eutrophication includes Ptot emission into water and soil, without discriminating the 
specific emissions (e.g. emission of phosphate and phosphoric acid are missing). For marine eutrophication, Ntot emissions into water and $\mathrm{NO}_{x}$ and $\mathrm{NH}_{3}$ to air are accounted for, whereas ammonium, nitrate and nitrite are missing.

Inventory data were available for two flows out of six for freshwater and three out of ten for marine eutrophication.

Overall, $68 \%$ of the eutrophication impact on freshwater is due to emissions of phosphorous to water and the remainder is from phosphorous emissions to soil. For what concerns marine eutrophication, $54 \%$ of the impact is due to emissions of nitrogen to water, $42 \%$ to emissions of $\mathrm{NO}_{x}$ to air and the remaining $4 \%$ to emissions of ammonia to air.

It should be noted that the original equation for estimating Ntot and Ptot only partially covers the industrial emissions to water, leading to a potential underestimation of the overall figures. Hence, such uncertainty sources represent the main limitation of the robustness of the normalisation factors for both marine and freshwater eutrophicationrelated impacts.

\subsection{Land use (LU)}

The inventory for 2010 for land occupation and land transformation is built from LULUCF (land use, land-use change and forestry) dataset derived from the national GHGs inventories (UNFCCC 2013). Existing data gaps (mainly for Cyprus and Malta) were filled by using the CORINE land cover maps (EEA 2012) and subsequent interpolation and extrapolations.

UNFCCC (2013), although having a good coverage of the total land uses and land-use changes, reports limited number of land use classes (5). Conversely, ILCD elementary flows are more detailed but the impact assessment model (Milà i Canals et al. 2007) provides only few characterisation factors (9 for occupation, 21 for transformation).

The flows contributing the most to the land use impacts in the domestic inventory 2010 are those related to land occupation. All together, they cover around $60 \%$ of the total impact in the EU 27. The remaining $40 \%$ is due to land transformation. Taken individually, the land transformation to artificial areas is the flow which contributes the most to land use, followed by land occupation due to agriculture, artificial areas, grassland and forests.

However, data on land use transformation to settlements are believed to be incorrectly reported within the UNFCCC for many of the EU countries. In fact, the total land use transformation to urban areas is unrealistically high if compared to other EU databases such as the Land cover and land use, landscape (LUCAS) (Eurostat 2013s; Eurostat 2014). Thus, estimates on the yearly transformation to urban areas (from any land use) were based on yearly changes in the extension of urban areas. The result led to a figure in line with to LUCAS reported statistics.

\subsection{Resource depletion-water (W)}

The total domestic resource depletion NF for water is calculated considering the gross freshwater abstraction from river and from the ground, for which characterisation factors are available for EU 27.

Data on water abstractions are from Eurostat (2013i), and were supplemented with OECD (2013b) and FAO-Aquastat (2013). Missing data were estimated using sector-specific coefficients of water withdrawals as reported in Sala et al. (2014). Data on water withdrawals for hydropower generation are not accounted within the NFs, consistently with the Swiss Ecological Scarcity impact assessment method (Frischknecht et al. 2009). In line with other impact categories, the generic $\mathrm{CF}$ for 'freshwater, OECD average scarcity' is used for the calculation; hence, no country-specific CF is used. A sensitivity analysis on regionalisation could be performed in order to assess how this aspect may influence the normalised results.

It should be noted that the NF calculated at EU level is based on an 'average scarcity' CF for OECD countries. If the datasets used in the LCIA phase contain processes with water abstraction in extra-EU countries with severe water scarcity and country-specific CFs are applied in the characterisation phase, this could result in a very high water depletion impact, relative to the other impacts. The totality of the impact is due to withdrawals of freshwater, with no distinction between surface and ground waters.

\subsection{Resources depletion—energy carriers, mineral and metals (RD-M)}

Resource depletion is associated to the following groups of resources: metals, minerals and primary energy sources. Data on extraction of metals (including uranium), minerals and primary energy sources is taken from British Geological Survey, EC (2014), PRODCOM and Eurostat. A detailed overview of the data sources is reported in Table 2.

Inventory data on metal, mineral and fossil resources are available for 34 out of 74 elementary flows for abiotic resources having a CF in the ILCD. Twelve metals (antimony, beryllium, germanium, indium, magnesium, molybdenum, niobium, tantalum, tellurium, titanium, thorium, vanadium) are not mined within the EU according to EC (2014) (11 according to USGS as beryllium is reported) but have characterisation factors available within the ILCD. The lack of data for some resources in the normalisation inventory implies a potential underestimation of the NF for this impact category. Several substances are not extracted in EU but imported; therefore, those are not contributing to EU NFs. This could lead to an overestimation of the relevance of the impact category RD-M compared to other impact categories when assessing products whose supply chain is heavily relying on imported resources. 
By applying reserve-based ADP characterisation factors (Van Oers et al. 2002), six materials contribute to $90 \%$ of the total resource depletion impact, namely strontium, silver, selenium, zinc, lead and arsenic. According to domestic extraction data, the contribution of energy carriers is negligible in comparison to minerals and metals, accounting for less than $1 \%$ of the total resource depletion. Among that fraction, uranium accounts for the highest share of the impact (33\%) followed by natural gas and crude oil.

Moreover, data on resource extraction can present some inconsistencies when comparing to different data sources, due to different computing systems or the use of coefficients to derive the content of elements from the mineral extracted. This is the case for strontium. In fact, according to BGS, the EU extractions of strontium in 2010 were $8.3 \mathrm{E}+04$ tonnes, while USGS reports a production of $1.4 \mathrm{E}+05$ tonnes. Using the USGS data, the contribution of the strontium to the total impact would rise from 30 to $41 \%$. Also for fossil fuels, figures from alternative data sources (IEA and USGS) differ from the ones provided by EUROSTAT. The use of different calorific power factors (in order to convert data on mass into energy values) is one reason for this difference in the results.

Additionally, the presence of co-products and by-products at, e.g. refinery stage, can lead to inconsistencies between different assessments. Moreover, statistics can provide data on mineral and metal production at different stages of the supply chain (e.g. bauxite and aluminium); this has been taken into account in order to avoid double counting.

\subsection{Toxicity-related impact: freshwater ecotoxicity (Etox) and human toxicity (HT)}

Emissions in air, water and soil affecting toxicity-related impact categories are collected from a variety of sources, both as direct raw data from source as presented in Table 2 and extrapolated through other background data (in case of the following: emission to soil from sludge and manure; emission of pesticides in air, soil and water; emission of pharmaceuticals to water). An overview of the extrapolation strategies is given in Sala et al. (2014) and in Cucurachi et al. (2014). Emissions from raw data and extrapolation strategies allow a coverage that is much more complete compared to previous inventories (1169 elementary flows for freshwater ecotoxicity, compared to 665 of $\mathrm{ReCiPe}_{2000}$ and 190 of $\mathrm{CML}_{2000} ; 184$-cancer, 692non-cancer elementary flows, compared to $524 \mathrm{ReCiPe}_{2000}$ and $184 \mathrm{CML}_{2000}$ ).

For Etox, the normalisation figures are dominated by zinc emitted to soil (40\%) followed by copper emitted to soil ( $20 \%), 17 \beta$-estradiol emitted to water $(4.5 \%)$, folpet emitted to soil $(4 \%)$ and zinc emitted to air $(2.5 \%)$. The relative contribution of the overall figures for Etox is as follows: $3.17 \mathrm{E}+12$ due to metals; $9.34 \mathrm{E}+11$ due to pesticides; 2.58 $\mathrm{E}+11$ due to other organics (including pharmaceuticals) and non-metals. A detailed analysis of the discrepancies between the contribution to the impact in $\mathrm{CML}_{2000}, \mathrm{ReCiPe}_{2000}$ and our inventory is reported in Benini et al. 2014b. Differences mainly arise from the use of different sources for the inventory and the use of different impact characterisation models.

For human toxicity cancer (HTc) effect, the impact is dominated by chromium emitted to soil (more than $56 \%$ due to sludge and manure) followed by formaldehyde (28\%) and chromium emitted to air (4.5\%).

For human toxicity non-cancer (HTnc) effect, the impact is dominated by metals, with zinc emitted in air contributing for $38 \%$, zinc emitted in soil for $21 \%$ and mercury emitted in air for $23 \%$.

Compared to previous inventories, the number of flows with inventory data is higher both due to increased availability of raw data (e.g. the number of substances covered in EPRTR) and implementation of extrapolation strategies (see Electronic Supplementary Material for details on sources and added value compared to previous inventories). Nonetheless, uncertainties related to the inventory used for both Etox and HT are high due to different aspects: (i) extensive use of extrapolation strategies; (ii) relative low coverage of the substances (even if higher compared to previous exercise, it is still limited compared to overall number of chemicals annually emitted); (iii) choice of the characterisation models (e.g. a possible overestimation of the characterisation factors related to metals is already known for USEtox, where those factors are marked as 'interim'); (iv) for a number of substances, possible outliers should be double checked, e.g. in case of Etox, the emission of pharmaceutical are based on sales volumes assuming no quantitative reduction from metabolism and wastewater treatment plants. Being the data estimated from sale statistic, this means that we assumed $100 \%$ of the sold quantity released in water. This of course may overestimate the contribution of pharmaceutical to the overall impact.

\subsection{Ionising radiations (IR)}

The impacts associated with 'ionising radiation-human health' are estimated for the inventory 2010 using the following: emissions of radionuclides to air and water from energy production (nuclear and coal); emissions of radionuclides to air and water from nuclear spent-fuel reprocessing; discharge of radionuclides from non-nuclear activities (radio-chemicals production and research facilities); discharge of radionuclides from offshore oil and gas industry; and emissions to air and water from the end-of-life scenario of gypsum boards.

The emissions associated with energy production are estimated on the basis of airborne and waterborne radionuclides emissions per gigawatt-hour of electricity generated from nuclear power plants, by combining UNSCEAR data on emissions factors (2008) for ${ }^{14} \mathrm{C},{ }^{3} \mathrm{H},{ }^{131} \mathrm{I}$ and nuclear energy 
production (Eurostat 2013r). Additional emissions of radionuclides coming from nuclear and hard-coal production are estimated using unit processes from Ecoinvent 3.01 (Weidema et al. 2013) for nuclear and hard coal and energy statistics (Eurostat 20131, m). The amount of radionuclides emitted from fuel reprocessing is estimated from UNSCEAR data (2008) based on emissions of ${ }^{3} \mathrm{H},{ }^{14} \mathrm{C},{ }^{60} \mathrm{Co},{ }^{90} \mathrm{Sr},{ }^{99} \mathrm{Tc},{ }^{129} \mathrm{I}$, ${ }^{106} \mathrm{Ru},{ }^{137} \mathrm{Cs}$ and ${ }^{241} \mathrm{Pu}$ and combined with spent-fuel processing statistics from the International Panel on Fissile Materials (IPFM) (Forwood 2008; Schneider and Marignac 2008). The data on radionuclides discharged from non-nuclear activities (including offshore oil and gas activity) were taken from the OSPAR Commission database (OSPAR 2013a, b, c), for those countries belonging to the OSPAR convention. No estimations for non-OSPAR countries were performed with exception of offshore oil and gas activity. The latter are estimated for the EU 27 countries based on average discharges per magajoule (lower heating value) of oil produced and combining the result with overall oil production figures (Eurostat $2013 \mathrm{~m}$ ). Emissions associated with end-of-life scenario of gypsum boards are estimated by combining Ecoinvent (v 3.01) (Weidema et al. 2013) unit processes and PRODCOM data (PRODCOM/Eurostat 2013).

Inventory data were available for 38 flows out of 42 for which there is a CF in ILCD.

It has to be noted that many of the flows which are quantified through the inventory ( 49 to air and 47 to water) are not actually included in the impact assessment phase due to lack of CFs.

The emissions contributing the most to this impact category in 2010 are as follows: ${ }^{14} \mathrm{C}$ to air, ${ }^{137} \mathrm{Cs}$ to water and ${ }^{60} \mathrm{Co}$ to water. They account respectively for 83,9 and $5 \%$ of the impact. Emissions of ${ }^{14} \mathrm{C}$ are due to both nuclear electricity production and nuclear fuel reprocessing, whereas emissions of ${ }^{137} \mathrm{Cs}$ and ${ }^{60} \mathrm{Co}$ are exclusively due to nuclear fuel reprocessing.

\section{Discussion on results, contribution analysis and uncertainty of the normalisation set}

Figure 1 reports a summary of the contribution analysis for each impact category, highlighting the substances which contribute the most to each category. The figure illustrates the relative contribution to the impact in each impact category. Data are presented as percentage of the overall impact. In the majority of the impact categories, few elementary flows account for more than $90 \%$ of the impacts, and for almost all impact categories (but resources and land use), a single flow is contributing more than $45 \%$ on the overall impact. This is in contrast with Heijungs et al. (2007) where it is stated that substances that dominate a certain impact category will rarely dominate a second or third impact category. Actually, the fact that for some impact categories few substances are driving the impact is linked with the following reasons: (i) for $\mathrm{CC}$, the quantity of $\mathrm{CO}_{2}$ emitted are very high; (ii) for AC, ET, EF and $\mathrm{EM}$, the underpinning models have CFs for few elementary flows (respectively $6,6,6,10$ ) and there is a significant difference in the CFs for the substances (e.g. for AC, NO has a $\mathrm{CF}$ of $1.13 \mathrm{~mol} \mathrm{H}_{\text {eq }}^{+}$whereas $\mathrm{NO}_{2}$ of $0.74 \mathrm{H}_{\text {eq }}^{+}$); (iii) for IR, there is a combination of high quantity in the inventory and high $\mathrm{CFs}$ for ${ }^{14} \mathrm{C}$; (iv) for toxicity-related impacts (e.g. for HTc, HTnc and Etox), leading role of metals is related to a possible overestimation of impacts in the underpinning model. A comparison of the contribution with previous NFs, namely $\mathrm{CML}_{2000}$ and $\mathrm{ReCiPe}_{2000}$, is reported in SI. In the different NFs sets, few substances dominate the overall impact associated to climate change, acidification, eutrophication presenting a similar contribution, whereas for other impact categories (e.g. toxicity) the contribution is different.

In general, a significant share of the impacts is related to energy (e.g. $\mathrm{CO}_{2}, \mathrm{PM}_{2.5}$ and $\mathrm{NO}_{x}$ ). Particularly, $\mathrm{NO}_{x}, \mathrm{SO}_{x}$, and $\mathrm{NH}_{4}$ present overall a very high contribution, namely to photochemical ozone depletion, acidification, and eutrophication terrestrial and marine, and particulate matter. Also ${ }^{14} \mathrm{C}$, contributing to ionising radiation, is due to electricity production and fuel reprocessing (around $80 \%$ of the emissions are associated to energy).

Giving that for some impact categories (e.g. AS, ET; EF, EM) the elementary flows are relatively limited, gathering inventory data for the separate specific substances could be very important, as substances belonging to the same group might have very different characterisation factors.

Regarding toxicity-related impact categories, metals are dominating the impact: $\mathrm{Cr}$ for human toxicity cancer and $\mathrm{Zn}$ for human toxicity non-cancer and ecotoxicity. Those elementary flows were mainly estimated and current figures reflect inputs from manure and sludge application to soil. The dominance of these flows on the total impact has to be interpreted in the light of the limitations that apply to the toxicity-related impact categories. In fact the characterisation factors for heavy metals are recommended with caution in the ILCD for the impact categories 'human toxicity-cancer effects', 'human toxicity, non-cancer effects', and ecotoxicity as this class of pollutants is characterised by very high and very uncertain CFs. However, the inclusion of new substances for HTc/nc and Etox (e.g. pharmaceutical) and activity-based proxies (e.g. emission of zinc from agriculture) changed the relative contribution compared to previous $\mathrm{NFs}\left(\mathrm{CML}_{2000}\right.$ and $\mathrm{ReCiPe}_{2000}$ ) and the results are in line with current concerns on priority substances. For example, the contribution for Etox is lead by zinc and copper, considered among the metals to be considered carefully due to its widespread occurrence in domestic, agricultural and industrial applications (SCHER 2012; EU 2013). Moreover, a share of contribution is associated to $17 \beta$-estradiol, recently included in the 1 st Watch List of 


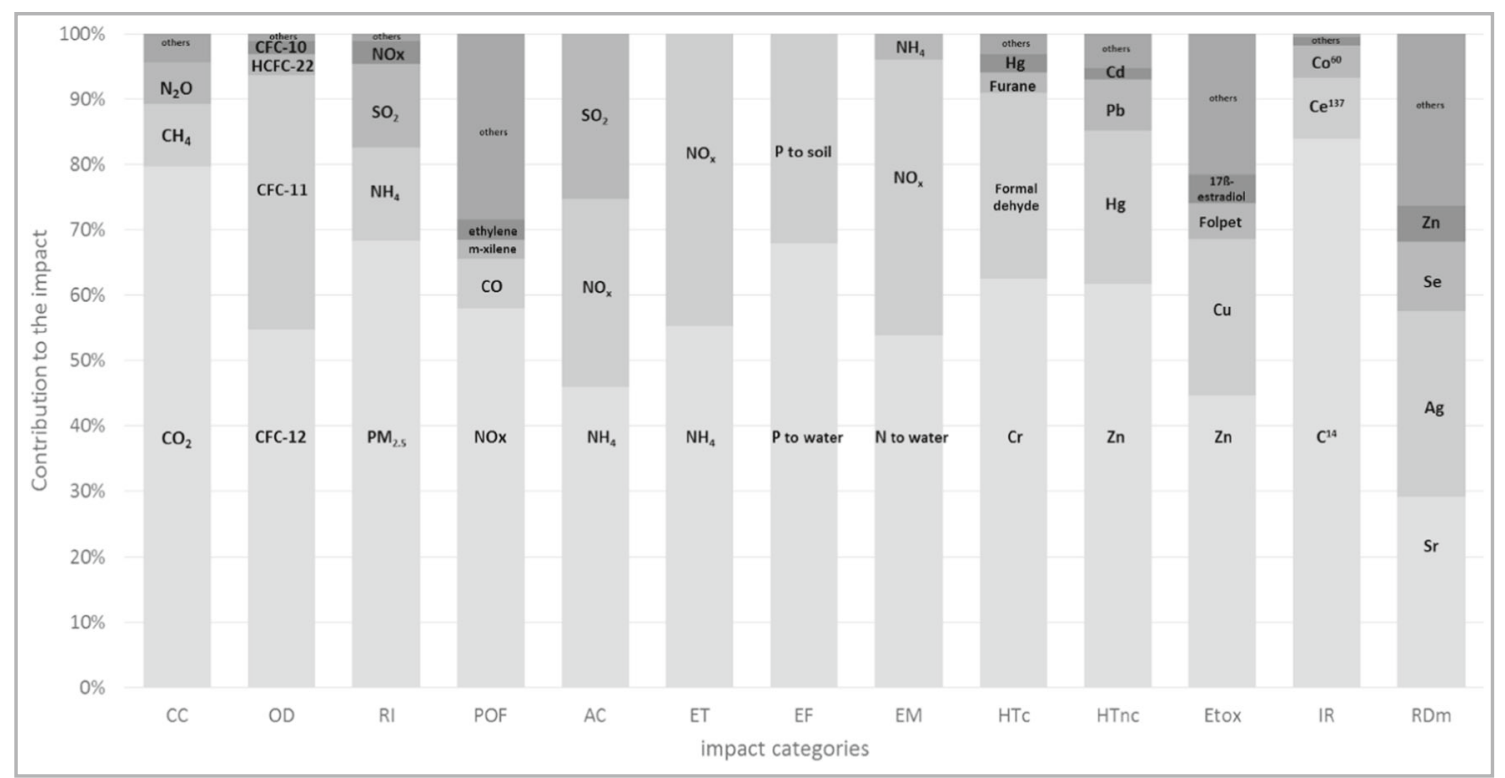

Fig. 1 Summary of the main contributors to the different impact categories, as percentage of the overall NF for the specific impact. $C C$ climate change; $O D$ ozone depletion; $R I$ respiratory inorganics; $P O F$ photochemical ozone formation; $A C$ acidification; $E T$ eutrophication

terrestrial; $E F$ eutrophication freshwater; $E M$ eutrophication marine; $H T c$ human toxicity cancer; HTnc human toxicity non-cancer; Etox freshwater ecotoxicity; $I R$ ionising radiation; $R D m$ resource depletion metals

Directive 2013/39/EU, EU (2013). A complete coverage of priority list of chemicals of concerns is still missing; however, the NFs are reflecting a better convergence among estimates in different contexts.

The majority of the impacts are due to land occupation by agriculture and urban activities, whereas the land use transformations play a relatively minor role.

Overall, a quantitative assessment of uncertainty was not possible because of the variety of sources of uncertainty and biases, which in many cases can hardly be quantified. In order to overcome such issue, a qualitative assessment of the robustness of the estimate is performed by ranking impact categories. The overall robustness of the NFs is assessed by applying the qualitative criteria for the evaluation of the completeness of the inventory, the robustness of inventory and impact assessment. CC and RI present a high overall robustness. OD, POF, AC, ET, resource depletion metals (RDm) and IR are medium; EF, EM are medium to low; LU, resource depletion water $(\mathrm{RDw})$ and the toxicity-related impact categories $(\mathrm{HTc}$, HTnc and Etox) are low.

The aim of this classification is twofold: on one hand, this may indicate where efforts should be focused in future development of normalisation factors (being regional or global) for improving the overall robustness; on the other end, the practitioner can set the level of robustness he/she might want to have. Indeed, the scoring may help the practitioner as it raises awareness about the robustness and reliability of the results. For instance, in case that the impact categories dominating the results of an LCIA are those which have a low or medium to low overall robustness score, the practitioner should consider performing a thorough sensitivity analysis during the interpretation step.

The interpreter of normalised LCIA results needs information on the extent to which the chosen reference system (Dahlbo et al. 2013), the completeness of the inventory and the impact assessment method influence the results. This information is usually missing, whereas it is transparently documented in this work (Table 3) supporting both better interpretation of the LCA results and detection of biased normalisation. Nevertheless, a sensitivity analysis on key sources of methodological uncertainty may help to complement the uncertainty assessment.

\section{Outlook}

Efforts towards a more robust inventory and NFs set should focus on the following aspects: methodological choices; completeness of the inventory; mapping of elementary flows; completeness and robustness of the impact assessment; uncertainty and sensitivity analysis.

Methodological choices Domestic normalisation factors based on yearly statistics might overlook some impacts due to the limitations in coverage and timeframe Heijungs et al. (2007). This study should be seen in the wider context of attempts to include trade (import and export) and aim at developing (apparent) consumption-based normalisation factors 
(see EC-JRC 2012). The domestic figures are the basis for any further exercise and strength and limitation should be well understood.

For many impact categories, the use of domestic normalisation factors may introduce a bias. In the case of the current set of NFs, impact categories for which a significant amount of the impact occurs outside EU are relatively underestimated. As a matter of fact, the EU 27 has reduced the extraction of raw materials over time, increasingly relying on imports. For instance, in 2010, the mass of energy carriers imported in the EU was twofold the mass of carriers extracted domestically (Schoer et al. 2012). Thus, when normalisation factors based on domestic data are used in the normalisation step, there is a substantial risk of overestimating the importance of that impact category, in comparison to what would happen if normalisation factors based on EU apparent consumption or global statistics were used. This emphasises the potential benefit of integrating the trade part, e.g. with a hybrid approach in order to ensure a robust evaluation of possible key sectors driving the impacts (e.g. based on top-down approaches such as the multiregional-environmental extended input output MREEIOTs) and a comprehensive evaluation of emissions and used resources (based on bottom-up). Additionally, as many methodological assumptions have been made (e.g. on using or not spatially differentiated CFs, on the system boundary, etc.), ideally both in the characterisation and normalisation, the same CFs and assumption should be used.

Completeness of the inventory The completeness of the inventory coverage is affected by the availability of data in the original sources and for building reliable proxy indicators. Also, not all the countries are providing the same set of data and this may lead to misleading NFs. Additionally, there are inconsistencies between data sources which requires a hierarchical approach for selecting sources. Concerning delayed emissions, the current inventory is reporting emissions that occur in a given year without accounting for delayed emissions (see Sleeswijk et al. 2008). For certain emissions, this may be relevant and should be taken into account in future developments.

Mapping elementary flows The proper mapping of statistics into elementary flows consistent to the ILCD format proved to be difficult for the characterisation. This is mainly due to (1) the different structure of the statistics usually available from international and national bodies and (2) the nomenclature used in the LCA methodology and their different aggregation level. In addition, several data available at the inventory cannot be accurately characterised either for the following: (i) inconsistencies in the flow naming, (ii) missing characterisation factors, (iii) being provided in the official sources as groups of substances and it is not possible to map them (e.g. $\mathrm{AOX}$, compounds based on $\mathrm{Cu}$ ) or (iv) being provided in the official sources as group of substances for which a representative substance could be identified among those available in the ILCD (e.g. 'Dioxins' mapped as 2,3,7,8tetrachlorodibenzo-p-dioxin) or an average among available flows could be calculated (e.g. BTEX from CFs for benzene, toluene, ethyl benzene, xylene). The lack of a specific breakdown of these substances may lead to an underestimation of different impact categories, particularly human toxicity and ecotoxicity. The SI reports all the inventory data which were not mapped into ILCD elementary flows. However, in future developments, those could be considered, e.g. E-PRTR reports emission of ' $\mathrm{Zn}$ and compounds (as $\mathrm{Zn}$ )' from facilities in EU. In the current inventory, such emission was mapped into the ILCD elementary flow 'Zinc'. Instead, breakdown strategies would be required in order to map this flow to specific Zn compounds or metal speciations.

Impact assessment The choice of the impact assessment methods for calculating normalisation factors may imply significant differences in the final figures even if the inventory is the same (see Benini et al. 2014b for a comparison of the relative contribution adopting alternative impact assessment methods based on CML and ReCiPe). The efforts towards more robust normalisation reference are needed both at the inventory and at the impact assessment side. Acknowledging the possible bias, we followed the recommendation proposed by Heijungs et al. (2007) to discuss the relevance of bias after filling data gaps. Indeed, a more robust normalisation reference is needed both at the inventory and at the impact assessment side, including more robust impact assessment methods as well as better coverage of substances for which inventory data is available (as single elementary flow or group of substances) but the characterisation is missing. Beyond their use as normalisation factors, the calculated figures allow an integrated assessment of environmental impact of Europe in 2010 based on available data sources. When applied in another context, the present exercise allows to assess strengths and limitation regarding data gap filling and estimation of potential environmental impacts. Decoupling economic growth from environmental pressure and impacts needs integrated assessment of impacts, to avoid a benefit in one impact category is leading impact in another one.

Uncertainty and sensitivity analysis As discussed above, several sources of uncertainties may affect the normalisation factors. In order to understand the relevance and the magnitude of such uncertainties, a sensitivity analysis on the following aspects is considered of a priority: (i) comparing results obtained from the selection of different data sources; (ii) the attribution of specific characterisation factors to group of substances (e.g. $\mathrm{NO}_{x}$ mapped into $\mathrm{NO}_{2}$ or $\mathrm{NO}$ ); (iii) the use of regionalized characterisation factors when available and (iv) modelling choice associated to the system boundaries (e.g. accounting input to soil from eutrophying substances). 


\section{Conclusions}

The objective of the current study is the development of normalisation factors for EU 27 for the year 2010, focusing on domestic emissions in air, water and soil, and resource extraction. The added values of this study are related to two aspects: (i) the underpinning inventory dataset is much more complete in terms of substances covered if compared with previous ones. On one hand, over the years, significant efforts have been made by national and international agencies to collect better data. On the other hand, the inventory is built on extensive use of extrapolation methodologies for data gap filling, impact category specific; (ii) the normalisation factors are subjected to qualitative evaluation based on data completeness, robustness of the estimation strategy and of the impact assessment method. The extended inventory is mainly based on authoritative sources of data (e.g. from monitoring campaign and official reporting from governmental bodies) coupled with proxy indicators, linking human interventions with emission estimates. The preference given to official statistics over modelling is related to the stakeholder acceptability of the figures and to the presence of quality controls.

Only CC and RI are qualitatively high, OD, POF, AC, ET and $\mathrm{RD}$ medium, whereas the others are medium to low or low. This suggests that future research should couple qualitative assessment of data and models with a systematic quantitative assessment of the uncertainty and sensitivity associated to modelling choices.

Notwithstanding the efforts for increasing coverage and robustness of the NFs, some limitations still exist and may lead to possible bias in the interpretation. These should be clearly communicated and understood to help interpreting LCA results after normalisation.

Acknowledgments The project to develop normalisation factors was financially supported by the Directorate General for the Environment (DG ENV) of the European Commission in the context of the Administrative Arrangement 'Environmental Footprint and Material Efficiency Support for Product Policy' (No. 70307/2012/ENV.C.1/635340). The authors would like to thank Malgorzata Goralczyk, Tommie Ponsioen, Rosalie Van Zelm and Alexis Laurent for their contribution to the inventory. Moreover, we thank two anonymous reviewers for their time and dedication in commenting the paper.

Compliance with ethical standards The authors declare that they have no conflict of interest.

Open Access This article is distributed under the terms of the Creative Commons Attribution 4.0 International License (http:// creativecommons.org/licenses/by/4.0/), which permits unrestricted use, distribution, and reproduction in any medium, provided you give appropriate credit to the original author(s) and the source, provide a link to the Creative Commons license, and indicate if changes were made.

\section{References}

Amlinger F, Pollak M, Favoino E (2004) Heavy metals and organics compounds from wastes used as organic fertilisers. EU Commission. Final report. REF.NR.: TEND/AML/2001/07/20

Bare J, Gloria T, Norris G (2006) Development of the method and U.S. normalization database for life cycle impact assessment and sustainability metrics. Environ Sci Technol 40(16): $5108-5115$

Benini L, Sala S, Manfredi S, Goralczyk M (2014a) Overall environmental impact indicators. Deliverable 3 of the Administrative Arrangement "Scientific support for screening and development of potential resource efficiency and product-group indicators as well as targets for the reduction of the overall environmental impact of EU consumption" DG ENV (N0 07.0307/2013/ 666404/SER/A.1)

Benini L, Mancini L, Sala S, Manfredi S, Schau EM, Pant R (2014b) Normalisation method and data for Environmental Footprints. European Commission, Joint Research Center, Institute for Environment and Sustainability, Publications Office of the European Union, Luxemburg, ISBN: 978-92-79-40847-2

Bouwman AF, Beusen AHW, Billen G (2009) Human alteration of the global nitrogen and phosphorus soil balances for the period 1970 2050. Glob Biogeochem Cy 23(4):GB0A04. doi:10.1029/ 2009GB003576

British Geological Survey (BGS) (1995) World Mineral Statistics 1990 1994. British Geological Survey, Keyworth Nottigham

British Geological Survey (BGS) (2000) World Mineral Statistics 1994 1998. British Geological Survey, Keyworth Nottigham

British Geological Survey (BGS) (2002) World Mineral Statistics 19962000. British Geological Survey, Keyworth Nottigham

British Geological Survey (BGS) (2012) European Mineral Statistics 2006-10. British Geological Survey, Keyworth Nottigham

CEC (2011) A resource-efficient Europe-flagship initiative under the Europe 2020 Strategy. Communication from the Commission to the European Parliament, the Council, the European Economic and Social Committee and the Committee of the Regions. COM (2011) 21 final

Chambers B, Nicholson N, Smith K, Pain B, Cumby T, Scotford I (2001) Managing Livestock Manures-Booklet 1: making better use of livestock manures on arable land. 2nd edition. Available at: http:// archive.defra.gov.uk/foodfarm/landmanage/land-soil/nutrient/ documents/manure/livemanure1.pdf.Accessed 25/02/2013

$\mathrm{CML}_{2000}$ (2015) Normalisatation factors for the year 2000. Available from http://cml.leiden.edu/software/data-cmlia.html\#downloads. Accessed January 2015

CORINAIR/EEA (2007) EMEP/CORINAIR Emission Inventory Guidebook-2007; Technical report No 16/2007. Published by the European Environmental Agency. Accessible electronically at the EEA website: http://www.eea.europa.eu/publications/ EMEPCORINAIR5/. Access to information for each (sub-) sector can be retrieved therein. Accessed on 10 Dec 2013

CORINAIR/EEA (2009) EMEP/CORINAIR Air Pollutant Emission Inventory Guidebook-2009; Technical report No 9/2009. Published by the European Environmental Agency. Accessible electronically at the EEA website: http://www.eea.europa.eu/ publications/emep-eea-emission-inventory-guidebook-2009. Accessed on Dec 2013

Cucurachi S, Sala S, Laurent A, Heijungs R (2014) Building and characterizing regional and global emission inventories of toxic pollutants. Environ Sci Technol 48(10):5674-5682

Dahlbo H, Koskela S, Pihkola H, Nors M, Federley M, Seppälä J (2013) Comparison of different normalised LCIA results and their feasibility in communication. Int J Life Cycle Assess 18(4):850-860 
EC (2010) Environmental, economic and social impacts of the use of sewage sludge on land. Final Report-Part III: Project Interim Reports. Eds. Milieu Ltd, WRc, RPA

EC (2014) Report on Critical Raw Materials for the EU. Report of the Ad hoc Working Group on defining critical raw materials. Available at http://ec.europa.eu/enterprise/policies/raw-materials/files/docs/crmreport-on-critical-raw-materials_en.pdf. Accessed June 2015

EC - European Commission (2001) Organic contaminants in sewage sludge for agricultural use. European Commission: Brussels, BE. Available at http://ec.europa.eu/environment/archives/waste/ sludge/pdf/organics_in_sludge.pdf. Accessed March 2015

EC - JRC \& PBL (Netherlands Environmental Assessment Agency) (2011) Emission Database for Global Atmospheric Research (EDGAR), release version 4.2. http://edgar.jrc.ec.europa.eu. Accessed Dec 2013

ECE - Economic Commission for Europe (2010) Hemispheric transport of air pollution 2010 part A: ozone and particulate matter. Eds: Dentener F. Keating T., Akimoto H. Prepared by the Task Force on Hemispheric Transport of Air Pollution acting within the framework of the Convention on Long-range Transboundary Air Pollution. Geneve and New York, United Nations

EC-JRC (2011a) Recommendations based on existing environmental impact assessment models and factors for life cycle assessment in European context. Luxembourg: Publications Office of the European Union. EUR24571EN. ISBN 978-92-79- 17451-3. Available at http://eplca.jrc.ec.europa.eu/

EC-JRC (2011b) EDGAR-HTAP: a harmonized gridded air pollution emission dataset based on national inventories. JRC Scientific and Technical reports. European Commission, Joint Research Centre, Institute for Environment and Sustainability. ISBN: 978-92-7923123-0. Available at http://bookshop.europa.eu/en/edgar-htappbLBNA25229/

EC-JRC (2012) Life cycle indicators framework: development of life cycle based macro-level monitoring indicators for resources, products and waste for the EU-27. Luxembourg: Publications Office of the European Union. EUR 25466 EN, ISBN 978-92-79-25937. Available at http://publications.jrc.ec.europa.eu/repository/ bitstream/111111111/31346/1/lbna25466enn.pdf

EEA (2012) Corine Land cover, Land accounts data viewer 1990, 2000, 2006. http://www.eea.europa.eu/data-and-maps/data/data-viewers/ land-accounts

EEA (2013a) European Pollutant Release and Transfer Register (E_PRTR)-Version 5 (17/05/2013) European Environmental Agency (EEA), Copenhagen, DK http://prtr.ec.europa.eu/ Accessed Dec 2013

EEA (2013b) Waterbase http://www.eea.europa.eu/data-and-maps/data/ waterbase-rivers-10. Accessed Dec 2013

EEA (2013c) National emissions reported to the Convention on Longrange Transboundary Air Pollution (LRTAP Convention). Available at http://www.eea.europa.eu/data-and-maps/data/nationalemissions-reported-to-the-convention-on-long-rangetransboundary-air-pollution-lrtap-convention-8. Accessed on 10 Dec 2013

EMEP/CEIP (2013a) Centre on Emission Inventories and Projections (CEIP) Country- and sector-specific pollutant emission data. Available at http://www.ceip.at/. Link to database: http://webdab1. umweltbundesamt.at/scaled country year.html?cgiproxy skip $=1$. Accessed on 10 Dec 2013

EMEP/CEIP (2013b) Present state of emissions as used in EMEP models. Available at http://www.ceip.at/webdab_emepdatabase/emissions emepmodels/. Accessed Dec 2013

EU (2013) Commission Recommendation of 9 April 2013 on the use of common methods to measure and communicate the life cycle environmental performance of products and organisations (2013/179/ EU). Official Journal of the European Union, Volume 56, 4 May 2013
European Union (EU) (2013) Directive 2013/39/EU of the European Parliament and of the Council amending Directives 2000/60/EC and 2008/105/EC as regards priority substances in the field of water policy

Eurostat (2013) Population on 1 January. Retrieved from http://epp. eurostat.ec.europa.eu/tgm/table.do? tab $=$ table \&init=1 \&language $=$ en\&pcode $=$ tps00001\&plugin $=1$. Accessed on Dec 2013

Eurostat (2013b) Demographic data. Eurostat Statistics Database; Available at: http://epp.eurostat.ec.europa.eu/portal/page/portal/ population/introduction

Eurostat (2013c) Use of sewage sludge applied to agricultural land - table [ten00030]. Eurostat Statistics Database; Available at: http://epp. eurostat.ec.europa.eu/tgm/refreshTableAction.do? tab= table \&plugin $=0 \&$ p code $=$ ten $00030 \&$ language $=e n$. Accessed June 2013

Eurostat (2013d). Land use - 1000 ha_-annual data [apro_cpp_luse] and crops products - annual data [apro cpp crop] Eurostat European Statistical Database. http://ec.europa.eu/eurostat

Eurostat (2013g) Gross Nutrient Balance [aei pr gnb] http://epp. eurostat.ec.europa.eu/portal/page/portal/product_details/dataset?p_ product_code=AEI_PR_GNB. European statistical database. Accessed May 2013

Eurostat (2013f). Sales of pesticides-Fungicides Code: tag00085 Eurostat European Statistical Database. http://ec.europa.eu/eurostat

Eurostat (2013h) Population connected to wastewater treatment plants [env_ww_con] European statistical database. http://epp.eurostat.ec. europa.eu/portal/page/portal/eurostat/home/. Accessed May 2013

Eurostat (2013i) Annual water abstraction by source and by sector [env_watq2] http://epp.eurostat.ec.europa.eu/portal/page/portal/ eurostat/home/. Accessed May 2013

Eurostat (20131) Supply, transformation, consumption - solid fuels - annual data (nrg_101a). http://epp.eurostat.ec.europa.eu/portal/page/ portal/statistics/search database. Accessed Dec 2013

Eurostat (2013m) Supply, transformation, consumption —oil—annual data (nrg_102a). http://epp.eurostat.ec.europa.eu/portal/page/portal/ statistics/search database. Accessed Dec 2013

Eurostat (2013n) Supply, transformation, consumption - gas - annual data (nrg_103a). http://epp.eurostat.ec.europa.eu/portal/page/portal/ statistics/search database. Accessed Dec 2013

Eurostat (2013o) Supply, transformation - nuclear energy — annual data (nrg_104a). http://epp.eurostat.ec.europa.eu/portal/page/portal/ statistics/search database. Accessed Dec 2013

Eurostat (2013p) Supply, transformation, consumption - renewables and wastes (total, solar heat, biomass, geothermal, wastes) - annual data (nrg_1071a). http://epp.eurostat.ec.europa.eu/portal/page/portal/ statistics/search database. Accessed Dec 2013

Eurostat (2013q) Supply, transformation, consumption - renewables (hydro, wind, photovoltaic) - annual data (nrg_1072a). http://epp. eurostat.ec.europa.eu/portal/page/portal/statistics/search_database. Accessed Dec 2013

Eurostat (2013r) Supply, transformation, consumption — electricity - annual data (nrg_105a) http://epp.eurostat.ec.europa.eu/portal/page/ portal/statistics/search_database. Accessed Dec 2013

Eurostat (2013s) Land cover/use statistics (LUCAS) - Introduction http:// epp.eurostat.ec.europa.eu/portal/page/portal/lucas/introduction

Eurostat (2014) Land cover/use statistics (LUCAS) - database http://epp. eurostat.ec.europa.eu/portal/page/portal/lucas/data/database

Fahey DW, Hegglin MI (2011) Twenty questions and answers about the ozone layer: 2010. Update, in Scientific Assessment of Ozone Depletion: 2010, Global Ozone Research and Monitoring Project-Report No. 52. World Meteorological Organization, Geneva, p 516

FAO-Aquastat (2013) The Food and Agriculture Organization of the United Nations-Aquastat http://www.fao.org/nr/water/aquastat/ main/index.stm 
FAOstat (2013a) Manure applied to Soils. http://faostat3.fao.org/home/ index.html\#DOWNLOAD. Accessed June 2013

FAOstat (2013b) Crop production quantities by country. The Food and Agriculture Organization of the United Nations; Link to database: http://faostat.fao.org/site/567/default.aspx\#ancor

FAOstat (2013c) Agricultural area certified organic. The FAO (Food and Agriculture Organization of the United Nations) Statistical Database. $h$ ttp://faostat.fao.org

FAOstat (2013d) Agri-Environmental Indicators - pesticides. The FAO (Food and Agriculture Organization of the United Nations) Statistical Database. http://faostat.fao.org

FAOstat (2013e) Pesticide use - triazoles, diazoles. The FAO (Food and Agriculture Organization of the United Nations) Statistical Database. http://faostat.fao.org

FAOstat (2013f) Average protein supply (g/capita/day) (3-year average). The Food and Agriculture Organization of the United Nations; provides food security indicators. Link to database: http://www.fao.org/

Forwood M (2008) The legacy of reprocessing in the United Kingdoma research report of the International Panel on Fissile Materials. Downloaded at: http://fissilematerials.org/library/rr05.pdf

Frischknecht R, Steiner R, Jungbluth N (2009) The Ecological Scarcity Method Eco-Factors 2006. A method for impact assessment in LCA, Bern

Hauschild M, Potting J (2005) Spatial differentiation in LCA impact assessment-the EDIP 2003 methodology. Environmental news No.80 2005. Danish Environmental Protection Agency. Copenhagen, Denmark. http://www2.mst.dk/udgiv/publications/ 2005/87-7614-579-4/pdf/87-7614-580-8.pdf. Accessed March 2015

Heijungs R, Guinée J, Kleijn R, Rovers V (2007) Bias in normalization: causes, consequences, detection and remedies. Int $\mathrm{J}$ Life Cycle Assess 12(4):211-216

Humbert S (2009) Geographically differentiated life-cycle impact assessment of human health. PhD Thesis. University of Berkeley. $265 \mathrm{p}$

Humbert S (2014) Personal communication by Sebastien Humbert, September 2014

IIASA (2013) GAINS - an interactive tool for assessing international GHG mitigation regimes. http://gains.iiasa.ac.at/gains/EUN/index. login?logout $=1$

ISO - International Standard Organisation (2006) Environmental management-life cycle assessment. Requirements and guidelines. ISO14044, Geneva

Jolliet O, Margni M, Charles R, Humbert S, Payet J, Rebitzer G, Rosenbaum R (2003) IMPACT 2002+: a new life cycle impact assessment methodology. Int J Life Cycle Assess 8(6):324-330

Laurent A, Hauschild MZ (2014) Impacts of NMVOC emissions on human health in European countries for 2000-2010: use of sectorspecific substance profiles. Atmos Environ 85:247-255

Laurent A, Lautier A, Rosenbaum RK, Olsen SI, Hauschild MZ (2011a) Normalization references for Europe and North America for application with USEtox ${ }^{\mathrm{TM}}$ characterization factors. Int $\mathrm{J}$ Life Cycle Assess 16(8):728-738

Laurent A, Olsen SI, Hauschild MZ (2011b) Normalization in EDIP97 and EDIP2003: updated European inventory for 2004 and guidance towards a consistent use in practice. Int J Life Cycle Assess 16(5): 401-409

Lautier A, Rosenbaum RK, Margni M, Bare J, Roy P, Deschênes L (2010) Development of normalization factors for Canada and the United States and comparison with European factors. Sci Total Environ 409(1):33-4

Milà i Canals L, Romanyà J, Cowell SJ (2007) Method for assessing impacts on life support functions (LSF) related to the use of 'fertile land' in life cycle assessment (LCA). J Clean Prod 15:1426-1440

OECD (2013a) Wastewater treatment (\% population connected) Organisation for Economic Co-operation and Development. http:// www.oecd.org/statistics/. Accessed May 2013
OECD (2013b) OECD Factbook 2013: Economic, Environmental and Social Statistics-water consumption. http:/www.oecd-ilibrary.org/ sites/factbook-2013-en/09/01/01/index.html?itemId=/content/ chapter/factbook-2013-68-en

OSPAR (2013a) Liquid Discharges from Nuclear Installations. Commission of the Convention for the Protection of the marine Environment of the North-East Atlantic (OSPAR). http://ospar.org/ content/content.asp?menu $=01511400000000 \_000000 \_000000$

OSPAR (2013b) Discharges of Radionuclides from the non-nuclear sectors. Commission of the Convention for the Protection of the marine Environment of the North-East Atlantic (OSPAR). http://ospar.org/ content/content.asp?menu $=01511400000000 \_000000 \_000000$

OSPAR (2013c) Discharges, Spills and Emissions From Offshore Oil and Gas Installations. Commission of the Convention for the Protection of the marine Environment of the North-East Atlantic (OSPAR). http://ospar.org/content/content.asp?menu $=01511400000000$ 000000000000

PRODCOM/Eurostat (2013) Survey on production of manufactured goods. http://epp.eurostat.ec.europa.eu/portal/page/portal/prodcom/ data/database

Rafaj P, Amann M, Siri J, Wuester H (2014) Changes in European greenhouse gas and air pollutant emissions 1960-2010: decomposition of determining factors. Clim Chang 124(3):477-504

Raw Material Group (RMG) (2013) Raw Materials Data and IntierraLive database, http://www.intierrarmg.com/Products/SNL_MnM_ Databases.aspx

$\mathrm{ReCiPe}_{2000}$ (2015) LCA ReCiPe midpoint normalisation 2000, version 1.1. Available from http://www.lcia-recipe.net/normalisation. Accessed January 2015

Rosenbaum RK, Bachmann TM, Gold LS, Huijbregts MAJ, Jolliet O, Juraske R, Koehler A, Larsen HF, MacLeod M, Margni M, McKone TE, Payet J, Schuhmacher M, van de Meent D, Hauschild MZ (2008) USEtox-the UNEP-SETAC toxicity model: recommended characterisation factors for human toxicity and freshwater ecotoxicity in life cycle impact assessment. Int J Life Cycle Assess 13(7):532-546

RPA (2006) Non-surfactant Organic Ingredients and Zeolite-based Detergents. Available at: http://ec.europa.eu/enterprise/sectors/ chemicals/files/studies/rpa non surf organ zeolites en.pdf

Sala S, Wolf MA, Pant R (2012) Characterisation factors of the ILCD Recommended Life Cycle Impact Assessment methods. Database and supporting information. First edition EUR25167EN. ISBN 97892-79-22727. Luxembourg: Publications Office of the European Union. Available at http://eplca.jrc.ec.europa.eu/uploads/2014/01/ LCIA-characterization-factors-of-the-ILCD.pdf

Sala S, Benini L, Mancini L, Ponsioen T, Laurent A, van Zelm R, Stam G, Goralczyk M, Pant R (2014) Methodology for building LCAcompliant national inventories of emissions and resource extraction. Background methodology for supporting calculation of Product Environmental Footprint normalisation factors. JRC scientific and policy report. EUR 26871. Luxembourg (Luxembourg): Publications Office of the European Union; 2014. JRC92036

SCHER (Scientific Committee on Health and Environmental Risks) (2012) Opinion on draft environmental quality standards under the Water Framework Directive - zinc, 22 March 2012, available at http://ec.europa.eu/health/scientific_committees/environmental_ risks/docs/scher o 157.pdf. Accessed June 2015

Schneider and Marignac (2008) Spent nuclear fuel reprocessing in France - a research report of the International Panel on Fissile Materials. Downloaded at: http://fissilematerials.org/library/rr04. pdfand resource efficiency indicators for EU. JRC science and policy report. EUR 26871, ISBN 978-92-79-43262-0

Schoer K, Giegrich J, Kovanda J, Lauwigi C, Liebich A, Buyny S, Matthias J (2012) Conversion of european product flows in to raw material equivalents. Final report of the project: assistance in the development and maintenance of Raw Material Equivalents 
conversion factors and calculation of RMC time series. Eurostat Contract no.50902.2010.001 - 2010.612. Institut für Energie und Umweltforschung, Heidelberg

Seppälä J, Posch M, Johansson M, Hettelingh JP (2006) Countrydependent characterisation factors for acidification and terrestrial eutrophication based on accumulated exceedance as an impact category indicator. Int J Life Cycle Assess 11(6):403-416

Sleeswijk AW, van Oers LFCM, Guinée JB, Struijs J, Huijbregts MAJ (2008) Normalisation in product life cycle assessment: an LCA of the global and European economic systems in the year 2000. Sci Total Environ 390(1):227-240

UNFCCC (2013) United Nations Convention on Climate Change http:// unfecc.int/ghg_data/ghg_data_unfccc/time_series_annex_i/items/ 3814.php. Accessed on June 2014

UNSCEAR (2008) UNSCEAR 2008 REPORT Vol. I. SOURCES OF IONIZING RADIATION. United Nations Scientific Committee on the Effects of Atomic Radiation. UNSCEAR 2008 Report to the General Assembly, with scientific annexes. Volume I: Report to the General Assembly, Scientific Annexes A and BUS-EPA (2006). Toxics Release Inventory (TRI) program. TRI Explorer.
United States Environmental Protection Agency (US-EPA), Washington DC, USA, 2006. At http://www.epa.gov/triexplorer

Van Drecht G, Bouwman AF et al (2003) Global modelling of the fate of nitrogen from point and nonpoint sources in soils, groundwater and surface water. Global Biogeochem Cy 17(4):26-1-26-20

Van Drecht G, Bouwman AF, Harrison J, Knoop JM (2009) Global nitrogen and phosphate in urban wastewater for the period 1970 to 2050. Glob Biogeochem Cy 23(4):GB0A03. doi:10.1029/ 2009GB003458

Van Hoof G, Vieira M, Gausman M, Weisbrod A (2013) Indicator selection in life cycle assessment to enable decision making: issues and solutions. Int J Life Cycle Assess 18(8):1568-1580

van Oers L, de Koning A, Guinee JB, Huppes G (2002) Abiotic resource depletion in LCA. Road and Hydraulic Engineering Institute. Ministry of Transport and Water, Amsterdam

Weidema BP, Bauer C, Hischier R, Mutel C, Nemecek T, Reinhard J, Vadenbo CO, Wernet G (2013). Overview and methodology. Data quality guideline for the ecoinvent database version 3 (final). Ecoinvent report No. 1 (v3)

World Mining Data (WMD) (2014) WORLD-MINING-DATA volume 29. Vienna. http://www.wmc.org.pl/sites/default/files/WMD2014.pdf 